\title{
PSICOLOGIA E PESQUISA DE MERCADO
}

\section{ENTREVISTA COM LOUISE LHULUER}

\author{
Psichology and market research
}

\author{
Interview with Louise Lhullier
}

Por Nanci Garcia Cairo ${ }^{1}$

Doutora em Psicologia Social, Louise Lhullier é fundadora e diretora de pesquisas do Instituto Ethos - de Pesquisa Aplicada, com sede em Curitiba, no Paraná. Com mais de vinte anos de experiência em consultoria organizacional, pesquisa e moderação de grupos, foi professora universitária antes de dedicar-se integralmente ao instituto. Nesta entrevista, Louise fala um pouco de sua trajetória, da importância da psicologia social para entender o consumidor e de oportunidades de trabalho.

Pergunta: Antes de trabalhar com pesquisa aplicada, em que área você atuava?

Resposta: Eu fui professora universitária durante muito tempo. Comecei a minha atividade acadêmica dando aula na PUC do Rio Grande do Sul. Quando eu saí, trabalhei em algumas empresas e depois fui para a Universidade Federal de Santa Catarina, de 1982 a 1996. Durante esse período eu também trabalhei fora, em projetos vinculados à Universidade, junto a órgãos públicos, principalmente. Eu dava consultoria na área de desenvolvimento gerencial e desenvolvimento de equipes. Além disso, fiz meu doutorado em psicologia social, era pesquisadora do CNPq, ocupei cargos administrativos, coordenei um grupo de pesquisa, publiquei livros e artigos, e atuei em organizações ligadas à pesquisa e produção científica.

Pergunta: E como surgiu a oportunidade de trabalhar com pesquisa de mercado?

1 Jornalista e colaboradora da Revista Psicologia Argumento - PUCPR.

Endereço para contato: R: Francisco Schaffer, 637 - Curitiba-PR CEP: 80820-200

E-mail: nancigc@terra.com.br 
Resposta: Comecei com pesquisa eleitoral, dentro da própria universidade. Como eu conhecia os instrumentos de pesquisa, fui solicitada a fazer uma pesquisa numa eleição para reitor. Em seguida, houve uma solicitação para fazer uma pesquisa para prefeito em Florianópolis. Nessa época eu estava vinculada a algumas pessoas que já haviam concluído sua formação na UFSC e que não estavam encontrando oportunidade de trabalho em pesquisa. Então nós resolvemos profissionalizar esta atividade e fundamos o Instituto Ethos, em 1992. A partir daí, começaram a aparecer outras modalidades de projetos, principalmente em pesquisa de mercado. E assim, fomos estudando mais, apesar dessa ser uma área em que o conhecimento se desenvolve e se acumula sem muito registro - muita coisa se transmite oralmente, até porque quem aprende ou desenvolve alguma coisa faz um certo segredo. Então se aprende muito fazendo, até mesmo errando, encontrando outras pessoas que trabalham na área e merecendo a confiança dessas pessoas para que elas nos contem sobre o que não deu certo na experiência delas. A gente juntou formação acadêmica com essa experiência prática e foi muito interessante.

Pergunta: Qual é a importância da psicologia social para entender o consumidor?

Resposta: A Psicologia Social é a base da pesquisa sobre comportamento do consumidor. Toda a fundamentação teórica você vai encontrar ali e em disciplinas associadas, como a própria sociologia e a antropologia. Mas a psicologia social é essencial porque te permite criar novas técnicas, ir além. E é impossível você trabalhar com pesquisa de mercado, como psicólogo ou como um analista que trabalha com planejamento e não é meramente um executor de tarefas, sem ter uma boa visão de psicologia do consumidor, sob as diversas linhas, abordagens e perspectivas teóricas. Isso é essencial para poder entender aquilo que se está vendo e saber o que perguntar, e depois, entender as respostas.

Pergunta: Isso é utilizado desde a preparação da pesquisa?

Resposta: Desde a própria concepção do projeto. No momento em que eu estou discutindo com o cliente o porquê da pesquisa, o que ele quer dessa pesquisa, eu tenho que saber onde eu estou me fundamentando para fazer uma crítica ou dar uma sugestão, e este onde inclui necessariamente o campo da psicologia do consumidor.

Pergunta: No mundo globalizado, você acha que o comportamento do consumidor é mais previsível, ou seja, é mais padronizado?

Resposta: Eu acho que a gente não pode falar de comportamento de consumidor como uma coisa homogênea. Há determinados produtos e serviços em que a gente observa um comportamento muito similar do consumidor aqui e em outros países de mesmo perfil cultural. Você pega vários países da América do Sul ou alguns países da América do Sul e países europeus, e observa comportamentos semelhantes. Isso se dá em produtos também muito globalizados. Mas há outras coisas em que o comportamento é muito particular. Então, existe tudo isso, algumas coisas podem ser trabalhadas de uma maneira mais global e outras, não. No geral, sempre é necessário dar algum tratamento localizado. Nós costumamos trabalhar em projetos internacionais, em parceria com alguns institutos e mesmo essas grandes empresas multinacionais costumam fazer estudos localizados, para ter uma visão de cada país. Além da pesquisa propriamente dita, eles costumam fazer consultas para saber da sua impressão, do seu feeling sobre aquele produto.

Pergunta: Junto com a globalização também surgiu um consumidor mais exigente. Isso significa que você tem que conhecê-lo cada vez melhor?

Resposta: Sim. Isso significa que as empresas, cada vez mais têm que se preocupar em ouvi-lo para conhecê-lo melhor. Por isso eu te falei da importância da psicologia social.

Pergunta: Você poderia dar um exemplo?

Resposta: Por exemplo, existem duas possibilidades de você interpretar um discurso. Uma maneira é sendo absolutamente linear. Você ouve e toma como verdadeiro o que a pessoa está te dizendo. Quando você pergunta se eu gosto de determinada marca de iogurte, e eu digo que gosto, a resposta é linear. Existem outras coisas, especialmente para alguns produtos, e isso 
é mais verdadeiro ainda para inovações, em que você tem que, além dessa leitura linear, superficial, explorar mais profundamente os sentimentos, as opiniões da pessoa que está sendo ouvida. Por quê? Posso te dar alguns exemplos. Primeiro, as pessoas, numa pesquisa, não gostam de deixar as perguntas sem resposta. E às vezes elas não têm uma opinião formada, mas na hora elaboram uma resposta qualquer. Outra coisa: se você quer que as pessoas colaborem com a pesquisa tem que estabelecer algum tipo de vínculo com elas, de tal forma que exista uma vontade de responder às perguntas para atender à demanda do entrevistador. Só que se essa vontade ultrapassa determinado nível, elas vão querer responder aquilo que você quer ouvir e vão ficar tentando adivinhar a "resposta certa". E um entrevistador não adequadamente treinado vai dar dicas, principalmente não verbais: um olhar, um sorriso, uma expressão da qual não se dá conta.

Então precisamos conhecer melhor esse consumidor, conhecer suas particularidades para poder atender aquilo que ele demanda. E é necessário conhecê-lo através dos procedimentos adequados, porque é possível fazer uma pesquisa muito cara, com muito cuidado e muita seriedade, mas por falta de atenção ao discurso " abaixo da superfície", Aos silêncios, aos atos falhos, àquelas coisas que a psicanálise nos ajudou a perceber, compreender e valorizar, o resultado pode ser enganoso, e pode causar um prejuízo muito grande para a empresa.

Em 1998 eu ganhei uma bolsa pela Universidade de Michigan, nos EUA, e apesar de estar trabalhando nisso há bastante tempo, fiz um curso específico sobre design de instrumentos de pesquisa. Às vezes, a colocação de uma palavrinha, a maneira como você encadeia as perguntas de um questionário, as opções de resposta que você coloca, influenciam o respondente de uma forma que não é intencional nem percebida, mas pode afetar significativamente os resultados.

Pergunta: Alguns estudiosos da sociedade pós-industrial, como o italiano Domenico De Masi, dizem que uma sociedade baseada nos serviços precisa de mais garantia e confiabilidade, do que aquela baseada apenas em bens materiais...

Resposta: A gente viveu uma derrubada de determinados valores e atualmente estamos passando por um momento de carência de valores nos quais a gente possa sustentar uma relação qualquer, uma relação amorosa, fraterna ou de negócios. Então, vemos hoje em dia o ressurgimento da afirmação de determinados valores em que as pessoas acreditam, não como algo absoluto, que vêm de fora, mas valores de escolha, sob os quais elas possam fundamentar sua vida e suas relações: uma ética. E nesse sentido eu acho que essa hipótese colocada pelo De Masi é muito provável. A gente, que está sempre em contato com o consumidor, vê muito isso. Ele se ressente bastante quando se sente enganado. $\mathrm{O}$ consumidor cobra uma consistência ética da parte das organizações, principalmente no segmento de serviços, mas também de produtos. Se isso não acontece na relação com uma determinada empresa ele vai buscar outra, vai fazer uma outra experiência, até que ele encontre uma, ou que lhe dê aquilo que ele espera, ou que lhe dê o melhor ou o mais próximo daquilo que ele espera, em termos de consistência e confiabilidade.

Pergunta: É possível inferir que a pesquisa de mercado se tornará cada vez mais necessária?

Resposta: Sim. Eu tenho absoluta certeza disso. Existe uma concepção de que a psicologia do consumidor e a pesquisa de mercado são alguma coisa voltada para a manipulação do consumidor. É verdade que existe, não na psicologia do consumidor, mas nas suas aplicações, um desejo de que seja possível esse controle. Ago$\mathrm{ra}$, a gente que trabalha com isso há mais tempo, percebe claramente o quanto é necessánio que uma empresa ou organização entre em sintonia com as demandas dos usuários dos seus produtos ou serviços. Há campanhas milionárias que são desenvolvidas, com imagens belíssimas e que são absolutos fracassos. Porque foi subestimada a participação ativa do consumidor nesse processo. $O$ que se tem que entender é que o processo de venda de um bem ou serviço é um processo de comunicação e se dá entre quem está vendendo e quem está comprando, é aí que ele ocorre. Não existe essa ascendência absoluta do vendedor sobre o comprador. Existe uma influência forte, mas essa influência tem que encontrar uma sensibilidade da parte do consumidor para que a coisa funcione. Eu diria que o mais promissor para quem 
quer vender um produto ou serviço é buscar essa sintonia, saber o que o consumidor está querendo, isso é fundamental.

Pergunta: $\mathrm{O}$ psicólogo que está preparado tem boas oportunidades na área de pesquisa de opinião e mercado?

Resposta: Tem. Faltam profissionais. Uma possibilidade de trabalho é na área de grupos, condução de grupos para pesquisa, grupos focais, por exemplo.A boa formação em psicologia e coordenação em dinâmica de grupo é um bom caminho. Mas se a pessoa não buscar trabalhar como estagiário em pesquisa, ter contato com as especificidades dessa área de aplicação do conhecimento, fica muito difícil.

Existe uma grande dificuldade do estudante, não só de psicologia, de ingressar nessa área. A principal delas é o desconhecimento de metodologia de pesquisa, não de metodologia específica, porque a técnica você aprende, mas de uma visão de como se constrói o conhecimento, a base sobre a qual a gente vai desenvolver o resto. Esse desconhecimento faz com que, muitas vezes, os estagiários não passem do nível que a gente chama de "tarefeiro", aquela pessoa que simplesmente executa uma tarefa, e aí há uma dificuldade de crescer dentro de uma empresa de pesquisa porque lhe falta a visão - o que é fazer uma pesquisa, afinal de contas, o que é buscar o conhecimento social e as possíveis abordagens. Em geral essas disciplinas de metodologia são dadas na primeira fase do curso e o estudante não lhes dá a devida importância.

O que eu gostaria de colocar é que, embora haja boas oportunidades para o psicólogo existe um mercado potencial - é necessário que ele busque uma visão multidisciplinar, que ele estude também antropologia, sociologia, a própria estatística, não para fazer testes estatísticos complicados, mas para ter uma boa base para desenvolver o trabalho.

Uma coisa que eu acho fundamental é o estudo da lógica, dentro da filosofia. Isso para qualquer função. Infelizmente baniram a filosofia de várias etapas da educação formal.

Pergunta: Você acha que a pesquisa de opinião poderia ser utilizada para melhorar a qualidade de vida dos grandes centros urbanos? Isso de alguma forma é feito no Brasil?

Resposta: No Brasil existem muitos órgãos públicos e organizações não governamentais que realizam periodicamente pesquisas de avaliação, tanto sobre a satisfação, quanto da demanda de determinadas regiões. Existem pesquisas bastante interessantes. Mas para que isso possa melhorar a qualidade de vida nos grandes centros urbanos é necessário que os resultados das pesquisas sejam utilizados na tomada de decisão sobre a vida das cidades. 